J. Dairy Sci. 96:7329-7339

http://dx.doi.org/10.3168/jds.2012-6017

(C) American Dairy Science Association ${ }^{\circledR}, 2013$. Open access under CC BY-NC-ND license.

\title{
Analysis of foot health records from 17 confinement dairies
}

\author{
J. M. DeFrain, ${ }^{1}$ M. T. Socha, and D. J. Tomlinson \\ Zinpro Corporation, Eden Prairie, MN 55344
}

\begin{abstract}
Foot health records are useful in monitoring the degree of lameness within dairy herds and, perhaps more importantly, providing insight into the underlying factors causing lameness. A database containing the incidence of foot lesions on large confinement dairy operations is largely unavailable but could prove useful to demonstrate the importance of collecting and analyzing foot lesion data to reduce lameness. Our objective was to merge foot lesion records from several dairy herds and establish a database to demonstrate how to use such data to better understand when and why foot lesions occur as an important means to manage lameness in dairy herds. The database consisted of $12 \mathrm{mo}$ of records from 17 dairies (14 freestall, 1 combination dirt lot and freestall, 2 dirt lot) representing 58,155 cows from herds ranging in size from 631 to 9,355 animals in 9 states from the United States and 2 herds located in the Southern Hemisphere. Data were partitioned and analyzed as 2 separate data sets: (1) herds recording only lame events (cows lame when examined; $\mathrm{n}=8$ ), and (2) herds recording both lame and routine trim events $(\mathrm{n}=9)$. Data were analyzed using PROC FREQ (SAS Institute Inc., Cary, NC) and significance was determined using Chi-square. White line disease, sole ulcer, toe ulcer, digital dermatitis, and foot rot comprised 93 and $40 \%$ (excluding routine trim with no lesion, $55 \%$ ) of lesions for herds recording only lame events and those recording lame and trim events, respectively. Ratio of infectious to noninfectious lesions decreased with increasing lactation number in both data sets. Digital dermatitis and foot rot were greatest in the first $60 \mathrm{~d}$ in milk and differed across lactation number. Noninfectious lesions were greatest following summer heat stress, whereas infectious lesions were greatest during the coolest quarter of the year. In conclusion, analysis of the foot health data from these dairies demonstrates that (1) infectious lesions of the foot skin and soft tissues predominate in early lactation and during cooler months of the year, and (2) noninfec-
\end{abstract}

Received August 1, 2012.

Accepted July 16, 2013.

${ }^{1}$ Corresponding author: jdefrain@zinpro.com tious lesions predominate during the 3 mo following summer heat stress and their distribution follows a typical lactation curve.

Key words: lameness, foot lesion, claw

\section{INTRODUCTION}

Efforts to reduce lameness in dairy cattle remain a priority as the industry strives to enhance animal well-being. When cows are assessed using locomotion scoring, the number of lame cows at any one time on intensively managed dairies can range from 20 to $25 \%$ (Cook, 2003; Espejo et al., 2006). Kelton et al. (1998) used data from 39 publications over a 23 -yr period and reported a median lactation incidence of $7 \%$, with a range of 1.8 to $30 \%$. All of these reports utilized locomotion scoring to quantify the prevalence of lameness.

Locomotion scoring has been globally adopted to determine the prevalence and severity of lameness. Perhaps more importantly, Bicalho et al. (2007) demonstrated that locomotion scoring is a useful tool to identify cows with painful lesions within the dairy herd. In general, the dairy industry has improved upon the identification and treatment of lame animals. The dairy claw lesion identification guide released by the International Lameness Committee (Greenough, 2008) is one of the newer tools available for assistance in identifying claw lesions. More accurate diagnosis and recording of foot lesions in the dairy industry will provide the data necessary to determine the major foot lesions expressed in dairy cattle so that we can further our understanding of causative factors of the major foot lesions affecting herd performance. This was most recently demonstrated using data collected over 2.5 yr from a 2,100-cow dairy in the southeastern United States (Sanders et al., 2009). However, reports available on the frequency of foot lesions expressed in dairy cattle are largely derived from noncommercial herds and quite limited in cow numbers.

Our objective was to merge foot lesion records from several large dairy herds to better understand when and why foot lesions occur and use these data to demonstrate to producers how accurate recording of foot lesions can be used to decrease lameness in their dairy herds. 


\section{MATERIALS AND METHODS}

Foot lesion data $(49,664$ events) from 17 dairies (14 freestall, 1 freestall with dirt lot access, 2 dirt lot) were collected from on-farm dairy herd management software. Data were collected once per dairy as a single file that included foot events of cows within the active cow file from the previous 12 mo such that each month of the year was represented only once per dairy. Data files were collected between July 2007 and April 2010, merged into one database, and used for analysis. Herd characteristics of dairies used to create the database are shown in Table 1. Data originated from approximately 58,155 Holstein cows $[16,403$ events from lactation 1 (L1), 14,449 events from lactation 2 (L2), and 18,812 events from lactation $>2(\mathbf{L}>\mathbf{2})]$ from herds ranging in size from 631 to 9,355 cows in 9 states in the United States and 2 herds located in the Southern Hemisphere. Milking occurred 2 or 3 times daily in milking parlors.

All participating dairies were involved in a previous project (DeFrain et al., 2009) associated with troubleshooting lameness. Approximately 3 mo before initiating data collection, foot trimming technique was evaluated and advised according to the method of $\mathrm{E}$. Toussaint-Raven (Toussaint-Raven et al., 1985). In addition, foot trimming personnel were trained on lesion identification and provided a dairy claw lesion identification poster as a reference guide, a poster developed by the International Lameness Committee (Greenough, 2008). This poster uses color photos of the various lesions along with typical claw zones affected by each lesion type. Each lesion on the poster has a 1-letter abbreviation code that was recorded by farm workers $(31,244$ events) and contract hoof trimmers $(18,420$ events) and entered into the herd management software by dairy office personnel.
With the exception of events in which no lesion was found $(30.4 \%), 51.6 \%$ of foot lesions reported were lesions shown on the dairy claw lesion identification poster. Nonstandard foot lesions recorded that were not identified on the poster included abscess $(7.2 \%)$, laminitis $(2.0 \%)$, and block (1.3\%). To standardize the foot lesion diagnosis before analysis of the database, it was necessary to visit the dairies recording these nonstandardized foot lesions so that feet could be visually inspected and the proper lesion diagnosis retrospectively included in the final database. In addition to examining these nonstandardized lesion types on live cows, hoof trimmers were asked to assign percentages to the claw zones depicted on the dairy claw lesion identification poster. The claw zones affected were then translated to lesion type and respective averages of these percentages were determined and randomly reassigned accordingly: abscess was assigned 50\% white line disease, $45 \%$ sole ulcer, and 5\% toe ulcer; laminitis was assigned $34 \%$ white line disease, $33 \%$ sole ulcer, and $33 \%$ sole hemorrhage; ulcer was assigned $95 \%$ sole ulcer and $5 \%$ toe ulcer; and block was assigned $50 \%$ white line disease, $45 \%$ sole ulcer and $5 \%$ toe ulcer. In addition, 1,158 events $(2.3 \%$ of all events recorded) were not included in the final data set because insufficient information was available to determine the type of lesion present.

The final database (Table 2) was partitioned and analyzed as 2 subsets of data: (1) herds recording only lame events (cows lame when examined; $\mathrm{n}=8 ; 15,019$ and 5,841 events from employees and contract hoof trimmers, respectively), and (2) herds recording both lame and routine trim events $(\mathrm{n}=9 ; 12,164$ and 15,482 events from employees and contract hoof trimmers, respectively). Counts were determined for each foot lesion within each subset of data. The PROC FREQ procedure (version 9.2; SAS Institute, 2008) was used

Table 1. Herd characteristics of dairies

\begin{tabular}{llcc}
\hline Dairy ID & Facility type & $\begin{array}{c}\text { Milking }+ \\
\text { dry cows, no. }\end{array}$ & Events, no. \\
\hline 1 & Freestall & 5,306 & 3,547 \\
2 & Dirtlot & 9,355 & 3,021 \\
3 & Freestall & 2,036 & 1,698 \\
4 & Freestall & 2,062 & 3,109 \\
5 & Freestall & 4,960 & 7,630 \\
6 & Freestall with dirtlot access & 3,736 & 2,993 \\
7 & Freestall & 5,533 & 1,773 \\
8 & Dirtlot & 1,455 & 604 \\
9 & Freestall & 1,041 & 968 \\
10 & Freestall & 631 & 806 \\
11 & Freestall & 1,862 & 4,331 \\
12 & Freestall & 1,928 & 3,396 \\
13 & Freestall & 2,485 & 3,497 \\
14 & Freestall & 3,228 & 1,725 \\
15 & Freestall & 2,436 & 2,922 \\
16 & Freestall & 931 & 586 \\
17 & Freestall & 9,170 & 7,058 \\
\hline
\end{tabular}


Table 2. Frequency of foot lesions recorded on 17 confinement dairies

\begin{tabular}{lrr}
\hline Lesion & No. & $\%$ \\
\hline None & 15,119 & 31.17 \\
Digital dermatitis & 13,498 & 27.83 \\
Sole ulcer & 6,447 & 13.29 \\
White line disease & 6,103 & 12.58 \\
Foot rot & 2,257 & 4.65 \\
Toe ulcer & 2,082 & 4.29 \\
Thin sole & 1,049 & 2.16 \\
Foreign body/other & 470 & 0.97 \\
Sole hemorrhage & 467 & 0.96 \\
Injury & 455 & 0.94 \\
Upper leg & 251 & 0.52 \\
Corkscrew & 98 & 0.20 \\
Axial fissure & 69 & 0.14 \\
Heel erosion & 43 & 0.09 \\
Interdigital hyperplasia & 43 & 0.09 \\
Vertical wall crack & 19 & 0.04 \\
Horizontal fissure & 16 & 0.03 \\
Digital sepsis & 14 & 0.03 \\
Hardship groove & 6 & 0.01 \\
\hline
\end{tabular}

to determine the percentages, and significance was determined using Chi-square at $P<0.05$ to identify differences among lesion type, lactation number (L1 vs. L2 vs. L $>2$ ), month, and DIM.

\section{RESULTS AND DISCUSSION}

The data reported herein are observational data collected from commercial dairies. Although we endeavored to reduce variation and error within the database, it is important to note the following when drawing inferences from this database: (1) no attempt was made to look at repeat events of the same cow identification number due to the use of similar cow identification numbers among herds, (2) the data were collected electronically from the active cow file and therefore excluded archived events from previous lactations and any cows that were previously culled or died, (3) intensity of lame cow identification and foot lesion data capture differed among herds, (4) proper diagnosis of the various foot lesions recorded was assessed by personnel collaborating with knowledge in foot lesions and foot health, most of who were past graduates of the Master Hoof Care Program at the University of Florida (Gainesville), and (5) treatment of the various foot lesions differed among herds.

\section{Herds Recording only Lame Events}

Frequency of foot lesions recorded on the 8 confinement dairies recording only lame events and excluding events where cows were trimmed and no lesion was present or recorded is shown in Table 3 . The 5 lesions recorded most frequently included digital dermatitis
Table 3. Frequency of foot lesions recorded on 8 confinement dairies that recorded only lame events and excluded events where cows were trimmed and no lesion was present or recorded

\begin{tabular}{lrc}
\hline Lesion & No. & $\%$ \\
\hline Digital dermatitis & 9,944 & 47.67 \\
Sole ulcer & 4,392 & 21.05 \\
White line disease & 3,601 & 17.26 \\
Foot rot & 930 & 4.46 \\
Toe ulcer & 544 & 2.61 \\
Foreign body/other & 469 & 2.25 \\
Sole hemorrhage & 299 & 1.43 \\
Thin sole & 275 & 1.32 \\
Upper leg & 128 & 0.61 \\
Corkscrew & 98 & 0.47 \\
Injury & 59 & 0.28 \\
Axial fissure & 50 & 0.24 \\
Interdigital hyperplasia & 39 & 0.19 \\
Vertical wall crack & 18 & 0.09 \\
Heel erosion & 8 & 0.04 \\
Hardship groove & 6 & 0.03 \\
\hline
\end{tabular}

(47.7\%), sole ulcer $(21.1 \%)$, white line disease $(17.3 \%)$, foot $\operatorname{rot}(4.5 \%)$, and toe ulcer $(2.6 \%)$; these 5 lesions accounted for $93.2 \%$ of the lesions recorded.

Digital dermatitis and sole ulcer were also reported as the 2 lesions occurring most frequently by Warnick et al. (2001), who found that digital dermatitis and sole ulcers accounted for 50.5 and $17.4 \%$ of foot lesions, respectively, in 19 mo of data collected on a 700-cow freestall-housed herd. Data from Warnick et al. (2001) are in agreement with data collected from 10 dairies in Wisconsin by Cook (2004), who found the prevalence of digital dermatitis, sole ulcers, and white line disease to be 57,18 , and $10 \%$, respectively. More recent data by Shearer and van Amstel (2007) found digital dermatitis to be $37.4 \%$ of foot lesions on a dairy $(3,221$ lactating cows) in the Midwestern United States. Somers et al. (2005) suggested that exposure of the foot to manure on the floor and subsequent contamination led to almost twice as many cows being affected with interdigital dermatitis and heel-horn erosion when cows were housed under confinement compared with on pasture (46 vs. $23 \%$, respectively). It is also plausible to consider that digital dermatitis can be more easily detected and diagnosed than claw horn lesions and therefore is more likely to be recorded by herd personnel.

Distribution of the 5 lesions recorded most frequently differed with lactation number and lesion type (Table $4 ; P<0.01)$. The frequency of recorded foot lesions for L1, L2, and L>2 was $32.9,27.6$, and $39.5 \%$, respectively (Table 4). The ratio of infectious (digital dermatitis and foot rot) to noninfectious claw lesions (white line disease, sole ulcer, and toe ulcer) decreased with increasing lactation number $(2.4,1.6$, and 0.7 for L1, L2, and L $>2$, respectively). Digital dermatitis accounted for 64.9 and $58.1 \%$ of foot lesions recorded for 
Table 4. Distribution of the 5 most frequently recorded lesions by lactation number on 8 confinement dairies that recorded only lame events and excluded events where cows were trimmed and no lesion was present or recorded

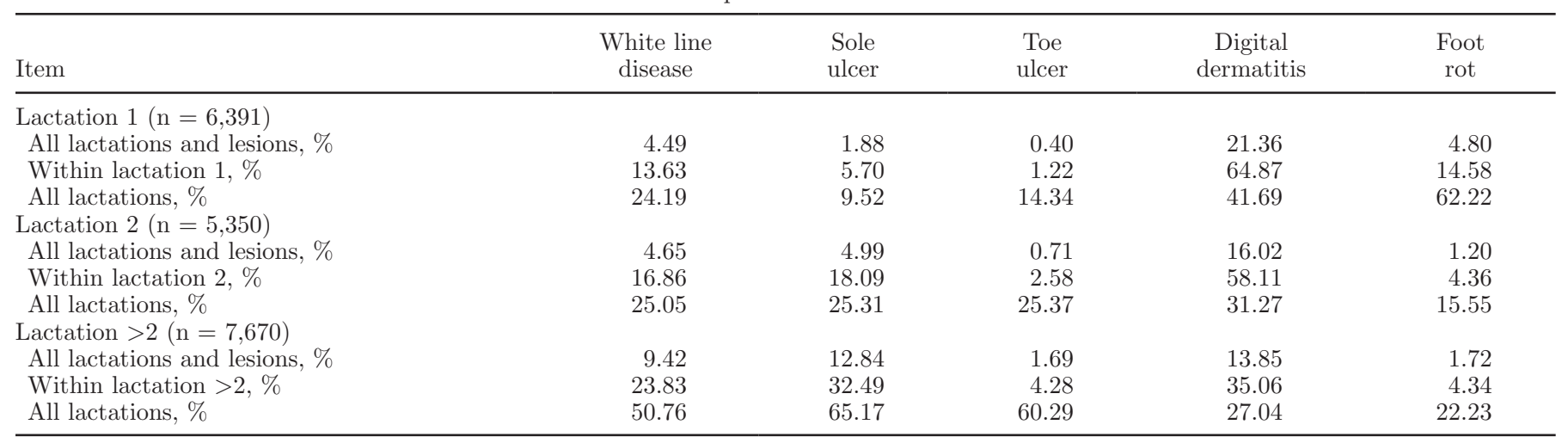

L1 and L2, respectively, and only $35.1 \%$ of lesions in $\mathrm{L}>2$. Differences noted among lactation number could be explained in part by differences in exposure of prepartum heifers to a preventative treatment for digital dermatitis, such as a footbath, which is often not used until animals enter lactating housing groups on the dairy.

Sole ulcers and white line disease are prevalent in North American dairy herds (Cook, 2003). The sum of white line disease and sole ulcer events, both of which are noninfectious lesions, was recorded in greater frequency in L > 2 compared with L1 and L2 groups ( $56.3 \%$ vs. 19.3 and $35.0 \%$, respectively). Using records from a 2,800-cow Holstein dairy in New York State housed on mattress-based freestalls, Bicalho et al. (2008) reported the combined incidence of sole ulcer and white line disease to be $10.3,24.5$, and $34.0 \%$ for L1, L2, and $\mathrm{L}>2$, respectively. Differences in our data and those of Bicalho et al. (2008) are likely due to differences in the size of the databases as well as the fact that Bicalho et al. (2008) defined sole ulcers and white line disease as cows receiving orthopedic blocks, which would not account for cows diagnosed with these lesions but not requiring an orthopedic block on the nonaffected claw. White line and sole lesions were also found to be more frequent in animals in lactation 4 compared with those in earlier lactations by Offer et al. (2000), who monitored foot lesions in 31 Holstein cows in a pasture-based system over 4 complete lactations. Taken together, all of these observations indicate a need for dairy herd managers to focus on preventing infectious lesions of the foot skin and soft tissues (i.e., digital dermatitis, interdigital dermatitis, and foot rot) in young stock and preventing noninfectious foot lesions in cows with $>1$ lactation.

Infectious and noninfectious lesions differed across month (Figure 1), and the ratio of infectious and noninfectious differed within month $(P<0.01$; data not shown). Infectious lesions of the foot skin and soft tissues were recorded more frequently during the cooler months of the year, whereas noninfectious lesions predominated during and after the warmer months. Both Sanders et al. (2009) and Shearer et al. (2006) found the highest incidence of noninfectious lesions (i.e., thin sole, thin sole toe ulcer, white line disease, and sole ulcer) in August and September when assessing data from herds in the southeastern United States. The increase in noninfectious lesions during and after heat stress is routinely observed and can be attributed to known changes in daily time budgets (Cook et al., 2007) and physiological adaptations, both of which result in greater risk for rumen acidosis and the subsequent production of inferior claw horn. In contrast, increases in infectious lesions of the foot skin and soft tissues during cooler months is most likely attributed to factors known to affect footbath efficacy, such as chemicals maintained at incorrect temperatures or damage occurring to the skin and horn barrier due to exposure of the foot to harsh environments (Nuss, 2006).

The distribution of the 5 most common foot lesions differed both across (Figure 2) and within (Figure 3) 60-d increments of DIM $(P<0.01)$. Almost half $(47.8 \%)$ of all events recorded were before 180 DIM, indicating the need to focus on factors known to cause lameness between the dry period and mid-lactation. The ratio of infectious to noninfectious lesions across DIM was 1.2 from 0 to 120 DIM, 0.8 from 120 to 300 DIM, and averaged 1.3 beyond 300 DIM (Figure 3). Stress, especially during the transition period, is an undesirable aspect of livestock production as it often results in immune dysfunction and increased likelihood of infection (Overton and Waldron, 2004). The combination of stress and immune dysfunction induced by parturition may help explain the increase in infectious claw lesions noted here in the first 120 DIM. This stress and immunosuppression interaction likely contributed 


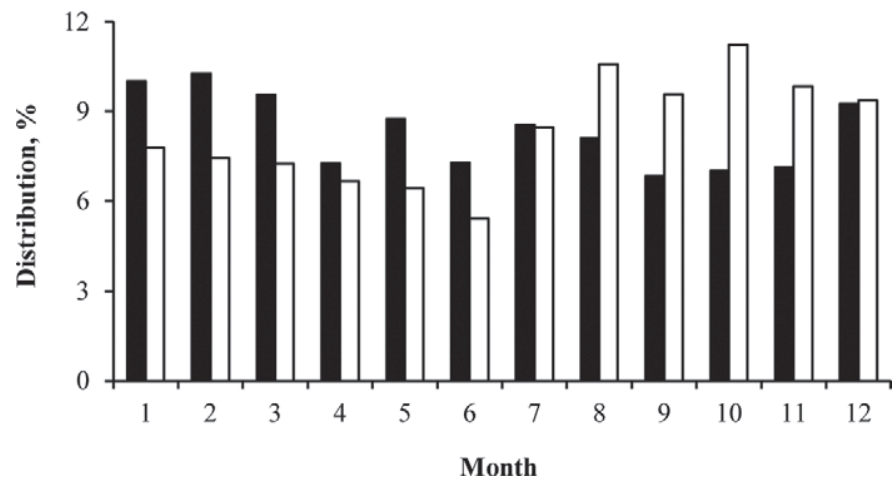

Figure 1. Distribution of infectious (digital dermatitis and foot rot; solid bars) and noninfectious (white line disease, sole ulcer, and toe ulcer; open bars) lesions across month on 8 confinement dairies that recorded only lame events and excluded events where cows were trimmed and no lesion was present or recorded $(\mathrm{n}=19,411)$.

to the high proportion of events $(41.9 \%)$ diagnosed as foot rot in the first 60 DIM. Data from 2 New York State herds representing 2,520 cows also found the majority of foot rot events $(58.7 \%)$ to occur within the first 60 DIM (Booth et al., 2004). Foot rot is an acute infectious disease with a short incubation period and rapid response to treatment (Whay et al., 1998) that likely resulted in the increase in events in early lactation shown in Figure 2.
The 2 most prominent foot lesions recorded in the first 120 DIM were digital dermatitis and sole ulcer (Figure 3). Although it was not possible to statistically analyze the 3-way interaction of lesion type, DIM, and lactation number, a few numerical differences were noteworthy. The percentage of events recorded as digital dermatitis within the first 120 DIM was greater for L1 and L2 cows than for $\mathrm{L}>2$ cows (63 and $61 \%$ vs. $39 \%$, respectively). However, more sole ulcer events were recorded for $\mathrm{L}>2$ cows compared with L1 and L2 cows during the same period (29\% vs. 14 and $15 \%$, respectively). Events recorded as digital dermatitis were evenly distributed across $60-\mathrm{d}$ increments of DIM and averaged $14 \%$ per 60 -d increment from 1 to 360 DIM, with the exception of $\mathrm{L}>2$ cows, in which digital dermatitis peaked at $23 \%$ in the first 60 DIM. In contrast, events recorded as sole ulcer and white line disease followed the shape of a typical lactation curve and peaked between 121 and 180 DIM (Figure 2). Others (Rowlands and Lucey, 1986; Hultgren et al., 2004) have found positive relationships between sole ulcers and white line disease and milk yield. Recently, Bicalho et al. (2009) concluded that a portion of the relationship between milk yield and claw horn diseases could be attributed to loss of body condition in early lactation and therefore a decrease in digital cushion thickness and the onset of sole ulcers. However, cows used by

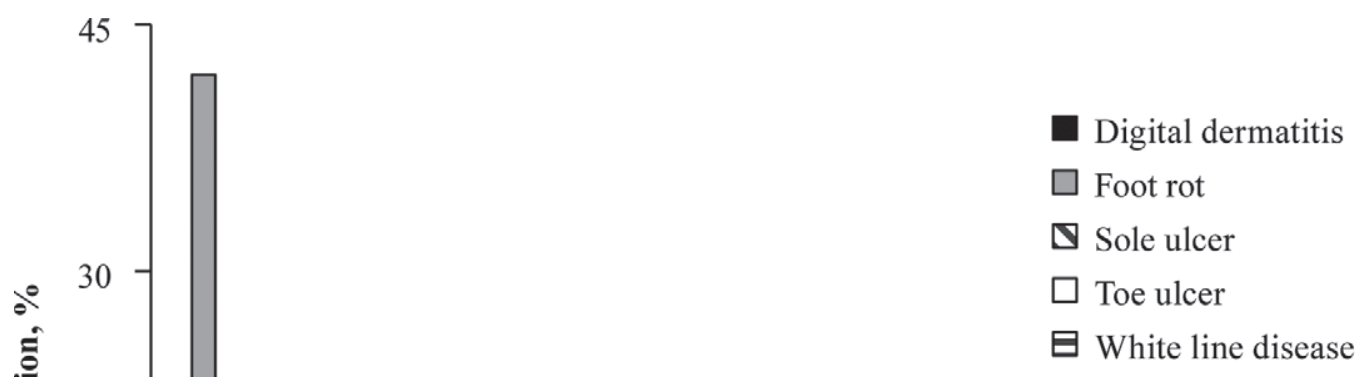
ment dairies that recorded only lame events and excluded events where cows were trimmed and no lesion was present or recorded $(\mathrm{n}=19,411)$. 
Digital dermatitis

Foot rot

Sole ulcer

Toe ulcer

日 White line disease

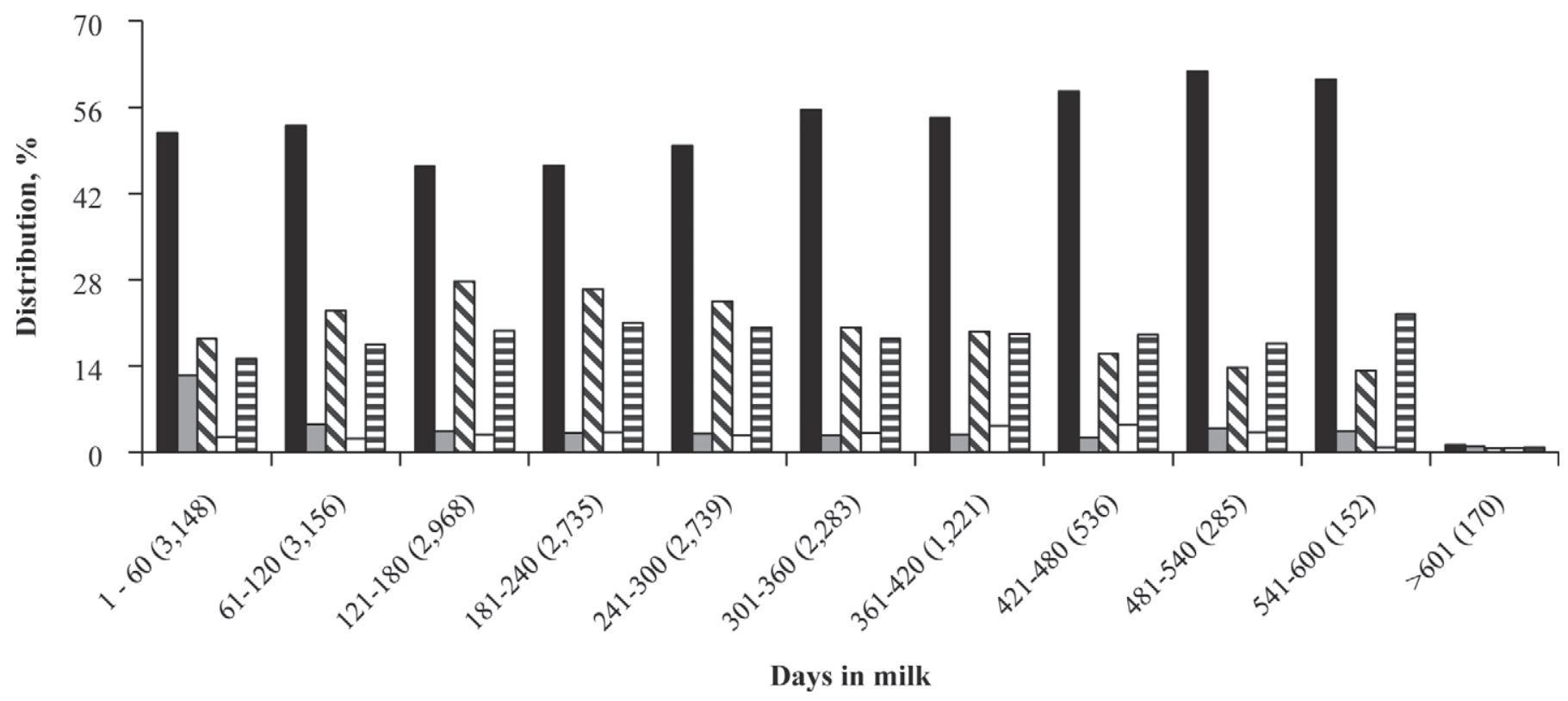

Figure 3. Distribution of digital dermatitis, foot rot, sole ulcer, toe ulcer, and white line disease within 60-d increments of DIM (values in parentheses following DIM ranges indicate number of cows within that category) on 8 confinement dairies that recorded only lame events and excluded events where cows were trimmed and no lesion was present or recorded.

Bicalho et al. (2009) were housed in a mattress-based freestall system, which has been shown to negatively affect lying times compared with sand-based freestalls (Cook et al., 2004). Differences in the distribution of infectious lesions and noninfectious foot lesions indicate that these 2 lesion classes require different methodical approaches when it comes to identifying causative factors and subsequently making management recommendations to reduce herd lameness.

\section{Herds Recording Lame and Trim Events}

In the experience of these authors, few herds record routine claw trimming events or events noting lame cows submitted to the trim chute with no foot lesion found. Setting aside the $54.7 \%$ of events recorded as no foot lesion present (Table 5), the 5 foot lesions with the greatest frequency in these 9 herds included digital dermatitis $(12.9 \%)$, white line disease $(9.1 \%)$, sole ulcer $(7.4 \%)$, toe ulcer $(5.6 \%)$, and foot rot $(4.8 \%)$. Not surprisingly, when looking at the distribution of foot lesions recorded (excluding events recorded as no foot lesion present), digital dermatitis was the major foot lesion recorded, accounting for $32.4 \%$ of the distribu- tion of the 5 lesions recorded in greatest frequency. It is important to record lameness disorders associated with the upper leg (nonfoot origin) because failing to record these events can underestimate the herd lameness relative to lameness prevalence detected using locomotion scoring. For example, Sanders et al. (2009) reported $6 \%$ lameness due to injuries compared with the nearly $2 \%$ found herein (Table 5). Understanding lameness associated with the foot as well as the upper leg is an essential component to understanding causes of lameness within the herd.

Compared with herds recording only lame events, the distribution of all events recorded in these herds was almost evenly distributed for L1, L2, and L>2 $(34.8,30.6$, and $34.7 \%$, respectively; Table 6$)$. However, the distribution of the 5 lesions recorded in greatest frequency differed among lactation number and lesion type $(P<0.01)$. Similar to herds recording only lame events, the ratio of infectious to noninfectious lesions decreased with increasing lactation number (1.6, 1.0, and 0.4 for L1, L2, and L>2, respectively).

The distribution of infectious and noninfectious foot lesions and events with no foot lesion found differed by month and lesion classification $(P<0.01$; Figure 
Table 5. Frequency of foot lesions recorded on 9 confinement dairies that recorded lame events and events where cows were trimmed and no lesion was found (none)

\begin{tabular}{lrr}
\hline Lesion & \multicolumn{1}{c}{ No. } & \multicolumn{1}{c}{$\%$} \\
\hline None & 15,119 & 54.69 \\
Digital dermatitis & 3,554 & 12.86 \\
White line disease & 2,502 & 9.05 \\
Sole ulcer & 2,055 & 7.43 \\
Toe ulcer & 1,538 & 5.56 \\
Foot rot & 1,327 & 4.80 \\
Thin sole & 774 & 2.80 \\
Injury & 396 & 1.43 \\
Sole hemorrhage & 168 & 0.61 \\
Upper leg & 123 & 0.44 \\
Heel erosion & 35 & 0.13 \\
Axial fissure & 19 & 0.07 \\
Horizontal fissure & 16 & 0.06 \\
Digital sepsis & 14 & 0.05 \\
Interdigital hyperplasia & 4 & 0.01 \\
Foreign body/other & 1 & $<0.01$ \\
Vertical wall crack & 1 & $<0.01$ \\
\hline
\end{tabular}

4). The distribution of events recorded across all 12 mo averaged $8.3 \%$ per month, ranging from a low of $6.1 \%$ in June to a high of $10.7 \%$ in February. Based on the distribution of lesion class (infectious, noninfectious, and events recorded as no foot lesion present) across all $12 \mathrm{mo}$, infectious lesions were greatest during the months of January through March, noninfectious lesions were greatest in September and October, and events recorded as no foot lesion present peaked in February, decreased through July, increased again through October, and then remained static. Interestingly, these seasonal trends existed with or without the data originating from the 2 herds located in the Southern Hemisphere (5,222 events). These data should only be used as an example, and the use of data within specific herds will prove more meaningful to management interventions to reduce foot lesions when it comes to understanding the months of greatest threat from infectious and noninfectious foot lesions.
Distribution of recorded events across 60-d increments of DIM suggests that the majority of herds have maintenance exams at mid-lactation (121-180 DIM) and at or near dry-off (301-360 DIM) based upon the high number of events recorded as no foot lesion present. The distribution of the 5 foot lesions recorded in the greatest frequency differed both across and within DIM range $(P<0.01 ;$ Figures 5 and 6$)$. Similar to herds recording only lame events, a high proportion of events in the first 60 DIM were infectious lesions relative to noninfectious foot lesions ( 22.2 vs. $14.5 \%$, respectively), an observation largely driven by the high proportion $(38.7 \%)$ of foot rot events. Although the statistical model did not allow for testing of differences of the 3-way interaction of lesion type, DIM, and lactation number because of insufficient observations, some numeric trends are worth noting as they align with routine field observations noted by the authors. Digital dermatitis within the first 60 DIM was found to be numerically greater in L1 and L2 groups than in L >2 (19.1, 25.6, and $15.9 \%$, respectively; data not shown). When looking across all 60-d intervals of DIM, 27.4\% of all digital dermatitis recorded in $\mathrm{L}>2$ cows were found in the first 60 DIM, whereas digital dermatitis events recorded for L1 and L2 groups were more evenly dispersed, averaging 14.6\% through 360 DIM (data not shown). Our data are in agreement with those of Argáez-Rodriguez et al. (1997), who found the highest risk for digital dermatitis to be in the first 30 DIM. Similar to our results, Holzhauer et al. (2006) found the risk for digital dermatitis to decrease with increasing lactation number, using foot lesion records from 383 herds in the Netherlands. This relationship may be a result of increased local immunity with age or culling of older affected cows (Frankena et al., 1991; RodriguezLainz et al., 1999; Somers et al., 2005).

Approximately $40 \%$ of foot rot events were recorded in the first 60 DIM, most of which were recorded in

Table 6. Distribution of the 5 most frequently recorded lesions by lactation number on 9 confinement dairies that recorded lame events and events where cows were trimmed and no lesion was found (none)

\begin{tabular}{|c|c|c|c|c|c|c|}
\hline Item & None & $\begin{array}{c}\text { White line } \\
\text { disease }\end{array}$ & $\begin{array}{l}\text { Sole } \\
\text { ulcer }\end{array}$ & $\begin{array}{l}\text { Toe } \\
\text { ulcer }\end{array}$ & $\begin{array}{c}\text { Digital } \\
\text { dermatitis }\end{array}$ & $\begin{array}{c}\text { Foot } \\
\text { rot }\end{array}$ \\
\hline \multicolumn{7}{|l|}{ Lactation $1(\mathrm{n}=9,069)$} \\
\hline All lactations and lesions, $\%$ & 22.39 & 2.17 & 1.20 & 1.49 & 5.50 & 2.00 \\
\hline All lactations, $\%$ & 38.64 & 22.66 & 15.28 & 25.23 & 40.38 & 39.41 \\
\hline \multicolumn{7}{|l|}{ Lactation $2(\mathrm{n}=7,979)$} \\
\hline All lactations and lesions, \% & 17.74 & 2.70 & 2.04 & 1.81 & 4.73 & 1.56 \\
\hline All lactations and lesions, \% & 17.82 & 4.71 & 4.63 & 2.60 & 3.40 & 1.52 \\
\hline Within lactation $>2, \%$ & 51.39 & 13.60 & 13.35 & 7.49 & 9.79 & 4.38 \\
\hline All lactations, $\%$ & 30.75 & 49.16 & 58.78 & 44.08 & 24.93 & 29.84 \\
\hline
\end{tabular}




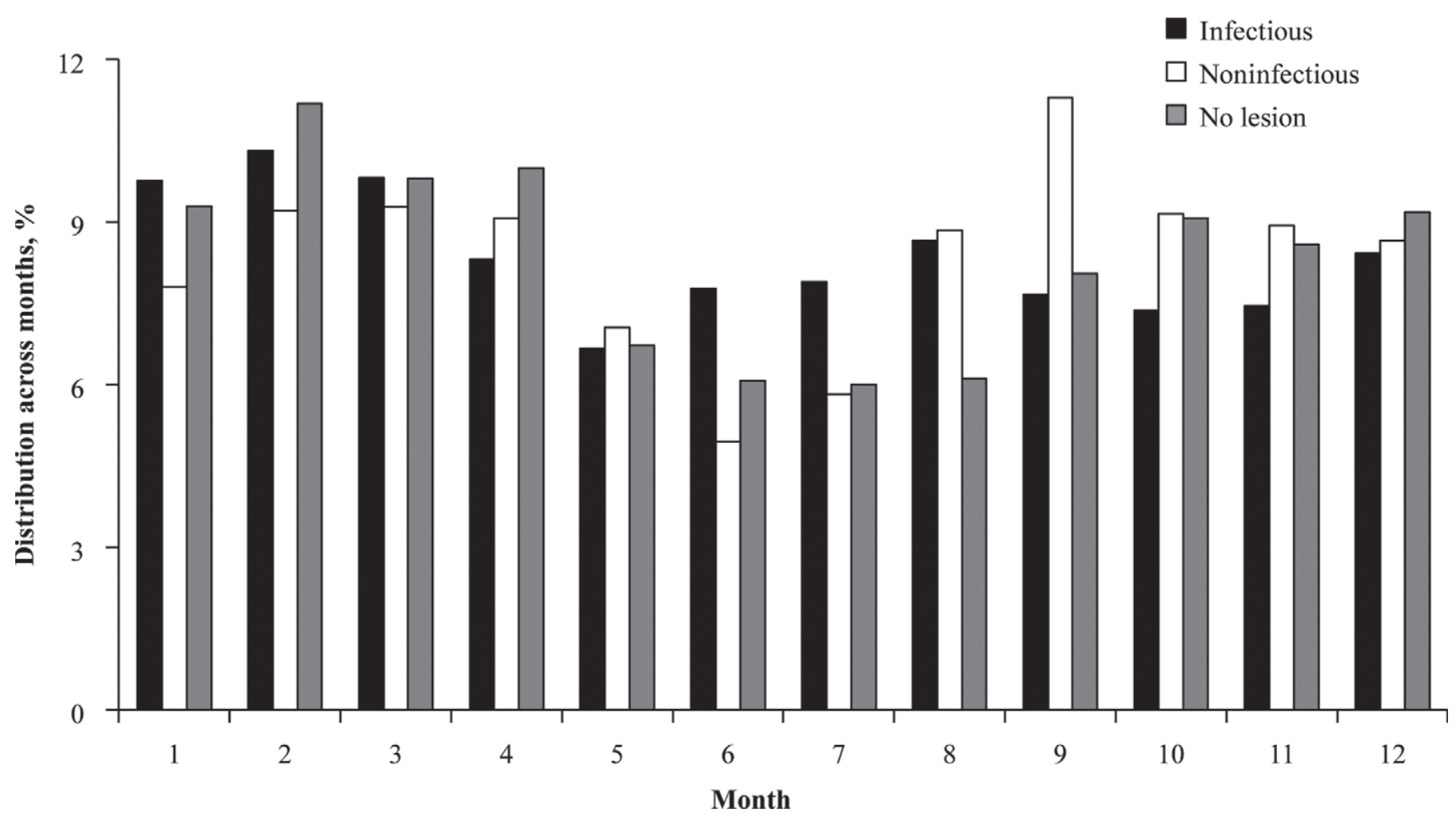

Figure 4. Distribution of infectious (digital dermatitis and foot rot) and noninfectious (white line disease, sole ulcer, and toe ulcer) lesions and events where cows were trimmed and no lesion was found by month on 9 confinement dairies $(\mathrm{n}=26,095)$.

L1 cows compared with L2 and L $>2$ cows $(30.5,17.3$, and $12.4 \%$, respectively). Using data from 2,520 cows in 2 New York State dairy herds, Booth et al. (2004) found foot rot to account for $58.7 \%$ of the foot lesions in the first 60 DIM. Clearly, infectious lesions of the foot skin and soft tissues dominate the early lactation period. Holzhauer et al. (2006) reported a positive association between digital dermatitis and other infectious disorders such as foot rot. Taken together with the distribution of digital dermatitis events, these data support the need to focus on management, prevention, and treatment of infectious diseases of the foot skin and soft tissues prepartum to avoid onset and spread of these foot lesions in early lactation, especially in L1 cows.

There were a few noteworthy observations made regarding noninfectious foot lesions. Sole and toe ulcers represented the majority of noninfectious claw lesions, increasing with increasing lactation number $(9.8,15.5$, and $27 \%$ for L1, L2, and L>2, respectively). Across all 60-d increments of DIM, the distribution of sole ulcers followed the shape of a typical lactation curve, although $\mathrm{L}>2$ cows had a lower peak and this peak was earlier (61-120 DIM) relative to that in L1 cows that peaked at 121 to 180 DIM. Booth et al. (2004) concluded that cows diagnosed with sole ulcers between 60 and 90 DIM were 2.7 times more likely to exit the herd. The delayed peak in sole ulcers in L1 cows might be a reflection of the first time that L1 cows received a routine or maintenance trim compared with multiparous cows that would have likely been trimmed and rebalanced at dry-off. In addition, this may also indicate difficulty of L1 cows in adjusting to lactation facilities, perhaps manifesting as increased time spent standing on concrete surfaces.

The distribution of toe ulcer and white line events by DIM and lactation number can be useful barometers for troubleshooting dairy cattle lameness. Toe ulcer events on dairies in our data set increased with increasing lactation number $(4.3,5.9$, and $7.5 \%$ for L1, L2, and $\mathrm{L}>2$, respectively) and peaked at roughly $20 \%$ from 1 to 60 DIM for L2 and L>2 groups and decreased with increasing DIM, whereas toe ulcer events for L1 cows had a normal, bell-shaped distribution and peaked at $23 \%$ at 241 to 300 DIM. Similar differences in timing (L2 and L>2 peaking earlier than L1) and height of peak events (L2 and L>2 peak greater than L1) were noted for events recorded as white line disease. Several factors could explain the differences noted between L1 and other lactations. One possible explanation might be the differences in transitioning into the lactation facility along with wear and growth rates of claw horn of 


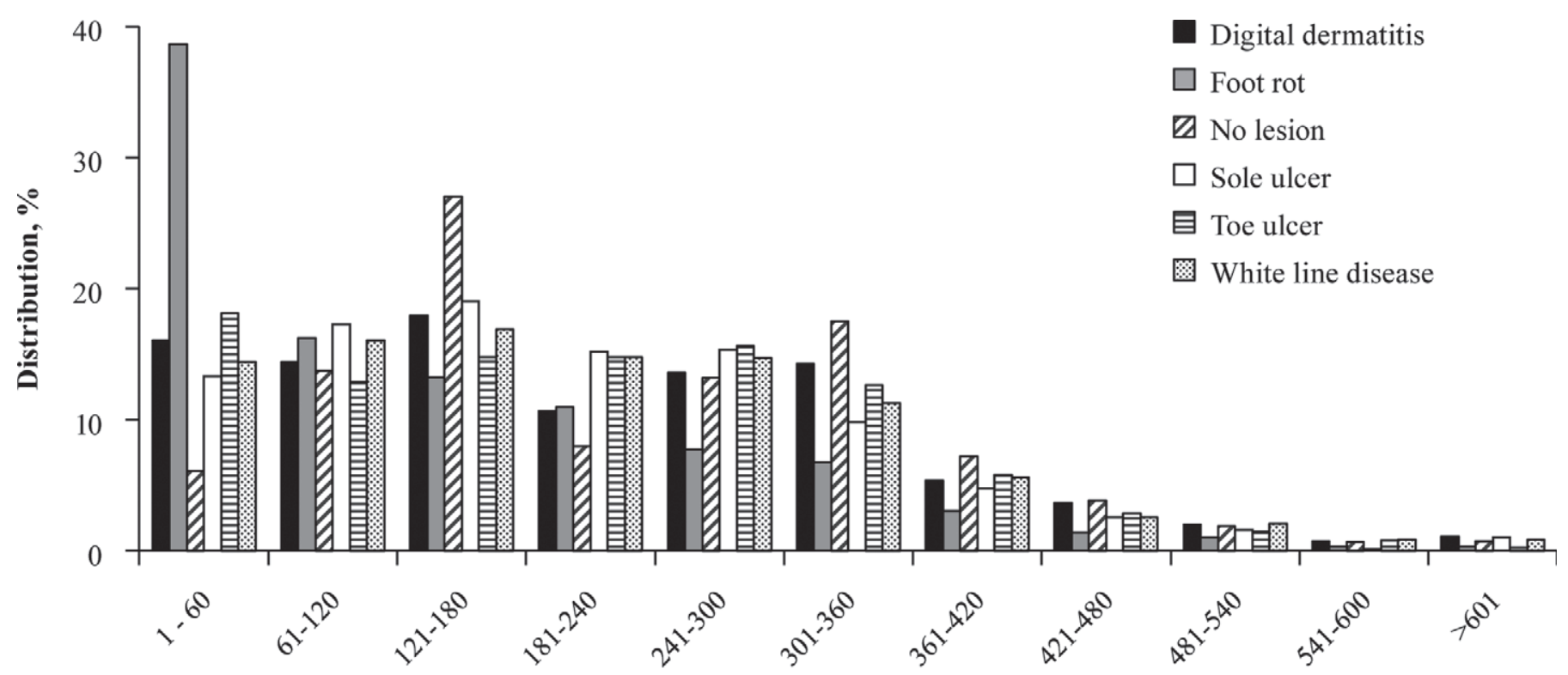

Days in milk

Figure 5. Distribution of digital dermatitis, foot rot, no lesion present, sole ulcer, toe ulcer, and white line disease across 60-d increments of DIM on 9 confinement dairies $(\mathrm{n}=26,095)$.

L1 cows. A second possibility could be related to overtrimming of the sole of $\mathrm{L} 1$ cows during the maintenance trim occurring between 121 and 180 DIM (assumption based off the peak in event recorded as no lesion present during this time), which may predispose cows to thin sole toe ulcer complex as described by Shearer and

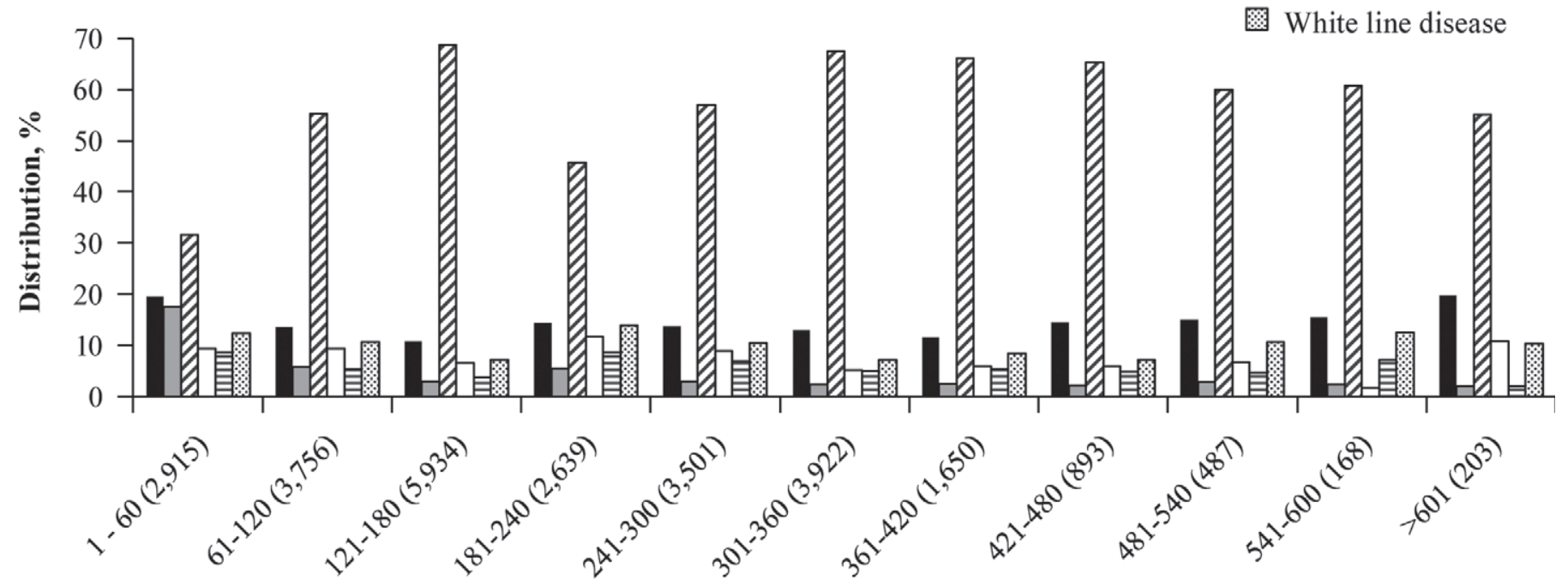

Days in milk

Figure 6. Distribution of digital dermatitis, foot rot, no lesion present, sole ulcer, toe ulcer, and white line disease within 60-d increments of DIM (values in parentheses following DIM ranges indicate number of cows within that category) on 9 confinement dairies $(\mathrm{n}=26,095)$. 
van Amstel (2010). Finally, and perhaps more commonly, animals completing their first lactation may be entering the dry period with thin soles $(<7 \mathrm{~mm}$ of sole depth) and are unable to regain sufficient horn growth before entering their next lactation. All of these are possible factors that should be evaluated when differences among lactation number and foot lesions exist within the dairy herd.

Bicalho et al. (2009) and Cook (2004) found toe lesions to make up less than $2 \%$ of lesions. Based on a database of foot health events derived from 578 dairy herds in the Canadian provinces of Alberta, British Columbia, and Ontario, toe ulcer events ranged from 1.7 to $4.9 \%$ (Mason, 2012) of all lesions diagnosed. According to Sanders et al. (2009), thin sole toe ulcers are commonly misdiagnosed as toe ulcers or white line disease, especially in large herds with long walking distances. The majority (1,282 of 2,082 events) of toe ulcer events reported in our database were from a single dairy. One possible explanation is the fact that this particular herd went through a significant nutritional challenge from poorly fermented forages, resulting in increased mobility of the third phalanx and subsequent greater frequency of toe ulcer events. However, nonnutritional factors (previously mentioned as overtrimming, transition issues, growth/wear rate, and so on) should not be ruled out in these cases because the dermal-epidermal segments only elongate and stretch (vs. completely separate in equines; Lischer and Ossent, 2002), which would give rise to more sole ulcers due to the sinking of the third phalanx versus forward rotation in the classic expression of toe ulcers. It should be noted that exclusion of toe ulcer events from this herd would result in toe ulcer events accounting for $1.6 \%$ of the lesions reported, which is in agreement with the numbers reported by others (Cook, 2004; Bicalho et al., 2009; Mason, 2012).

\section{CONCLUSIONS}

These data can be used to promote the usefulness of diagnosing foot lesions and recording the data on commercial dairies. Within the database described herein, infectious lesions, namely digital dermatitis and foot rot, appear to be the most troublesome in the first 120 DIM, especially in L1 cows. Conversely, noninfectious claw lesions (white line disease, sole ulcer, and toe ulcer) were largely associated with L2 and L $>2$ cows at or near peak milk production and during or shortly after periods of heat stress. We recommended that producers utilize the dairy claw lesion identification poster to accurately diagnose and record foot lesions so that these data can be analyzed, as demonstrated herein, as a means to reduce dairy cattle lameness. In addition, initial focus should be on proper diagnosis and recording of the major foot lesions affecting the herd, especially when introducing a foot health records program or when foot trimmers may have compromised literacy or language skills. Analysis of these records allows one to orchestrate lameness mitigation plans to successfully prevent, control, and manage foot lesions to enhance overall dairy performance and animal well-being within each dairy.

\section{ACKNOWLEDGMENTS}

Appreciation is extended to the dairies contributing to the database and to Nancy Whitehouse (University of New Hampshire, Durham) for statistical analysis.

\section{REFERENCES}

Argáez-Rodriguez, F., D. W. Hird, J. Hernandez de Anda, D. H. Read, and A. Rodriguez-Lainz. 1997. Papillomatous digital dermatitis on a commercial dairy farm in Mexicali, Mexico: Incidence and effect on reproduction and milk production. Prev. Vet. Med. 32:275286.

Bicalho, R. C., S. H. Cheong, G. Cramer, and C. L. Guard. 2007. Association between a visual and an automated locomotion score in lactating Holstein cows. J. Dairy Sci. 90:3294-3300.

Bicalho, R. C., V. S. Machado, and L. S. Caixeta. 2009. Lameness in dairy cattle: A debilitating disease or a disease of debilitated cattle? A cross-sectional study of lameness prevalence and thickness of the digital cushion. J. Dairy Sci. 92:3175-3184.

Bicalho, R. C., L. D. Warnick, and C. L. Guard. 2008. Strategies to analyze milk losses caused by diseases with potential incidence throughout the lactation: A lameness example. J. Dairy Sci. 91:2653-2661.

Booth, C. J., L. D. Warnick, Y. T. Gröhn, D. O. Maizon, C. L. Guard, and D. Janssen. 2004. Effect of lameness on culling in dairy cows. J. Dairy Sci. 87:4115-4122.

Cook, N. B. 2003. Prevalence of lameness among dairy cattle in Wisconsin as a function of housing type and stall preference. J. Am. Vet. Med. Assoc. 223:1324-1328.

Cook, N. B. 2004. Lameness treatment rates in Wisconsin dairy herds. Pages 50-51 in Proc. 13th Int. Symp. Lameness Ruminants, Maribor, Slovenia. B. Zemljic, Maribor, Slovenia.

Cook, N. B., T. B. Bennett, and K. V. Nordlund. 2004. Effect of free stall surface on daily activity patterns in dairy cows with relevance to lameness prevalence. J. Dairy Sci. 87:2912-2922.

Cook, N. B., R. L. Mentink, T. B. Bennett, and K. Burgi. 2007. The effect of heat stress and lameness on time budgets of lactating dairy cows. J. Dairy Sci. 90:1674-1682.

DeFrain, J. M., M. T. Socha, D. J. Tomlinson, and N. B. Cook. 2009. Evaluation of 14 western dairy herds using FirstStep ${ }^{\mathrm{TM}}$ : A novel tool to troubleshoot and prevent lameness in dairy herds. Page 264 in 42nd Annu. Conv. Proc. Am. Assoc. Bovine Pract., Omaha, NE, USA. Am. Assoc. Bovine Pract., Auburn, AL.

Espejo, L. A., M. I. Endres, and J. A. Salfer. 2006. Prevalence of lameness in high-producing Holstein cows housed in freestall barns in Minnesota. J. Dairy Sci. 89:3052-3058.

Frankena, K., E. N. Stassen, J. P. Noordhuizen, J. O. Goelema, J. Schipper, H. Smelt, and H. Romkema. 1991. Prevalence of lameness and risk indicators for digital dermatitis during pasturing and housing of dairy cattle. Pages 107-118 in Proc. Annu. Symp. Soc. Vet. Epidemiol. Prev. Med., London, UK.

Greenough, P. 2008. Nomenclature and atlas update. Page 40 in Proc. 15th Int. Symp. Lameness in Ruminants, Kuopio, Finland. Savonia University of Applied Sciences, Kuopio, Finland. 
Holzhauer, M., C. Hardenberg, C. J. M. Bartels, and K. Frankena. 2006. Herd- and cow-level prevalence of digital dermatitis in the Netherlands and associated risk factors. J. Dairy Sci. 89:580-588.

Hultgren, J., T. Manske, and C. Bergsten. 2004. Associations of sole ulcer at claw trimming with reproductive performance, udder health, milk yield, and culling in Swedish dairy cattle. Prev. Vet. Med. 62:233-251.

Kelton, D. F., K. D. Lissemore, and R. E. Martin. 1998. Recommendations for recording and calculating the incidence of selected clinical diseases of dairy cattle. J. Dairy Sci. 81:2502-2509.

Lischer, C. J., and P. Ossent. 2002. Pathogenesis of sole lesions attributed to laminitis in cattle. Pages 82-89 in Proc. 12th Int. Symp. Lameness in Ruminants, Orlando, FL. J. K. Shearer, ed.

Mason, S. 2012. The Alberta Dairy Hoof Health Project: Preliminary results point to high prevalence of digital dermatitis and claw horn disruption. Accessed Jan. 15, 2013. http://www.hoofhealth.ca/ article1_10.html.

Nuss, K. 2006. Footbaths: The solution to digital dermatitis? Vet. J. 171:11-13.

Offer, J. E., D. McNulty, and D. N. Logue. 2000. Observations of lameness, hoof conformation and development of lesions in dairy cattle over four lactations. Vet. Rec. 147:105-109.

Overton, T. R., and M. R. Waldron. 2004. Nutritional management of transition dairy cows: Strategies to optimize metabolic health. J. Dairy Sci. 87(E. Suppl.):E105-E119.

Rodriguez-Lainz, A., P. Melendez-Rentamal, D. W. Hird, D. H. Read, and R. L. Walker. 1999. Farm- and host-level risk factors for papillomatous digital dermatitis in Chilean dairy cattle. Prev. Vet. Med. 42:87-97.

Rowlands, G. J., and S. Lucey. 1986. Changes in milk yield in dairy cows associated with metabolic and reproductive disease and lameness. Prev. Vet. Med. 4:205-221.

Sanders, A. H., J. K. Shearer, and A. De Vries. 2009. Seasonal incidence of lameness and risk factors associated with thin soles, white line disease, ulcers, and sole punctures in dairy cattle. J. Dairy Sci. $92: 3165-3174$

SAS Institute. 2008. SAS User's Guide: Statistics. Version 9.2. SAS Institute Inc., Cary, NC.

Shearer, J. K., and S. R. van Amstel. 2007. Effect of flooring and/ or flooring surfaces on lameness disorders in dairy cattle. Pages 149-160 in Proc. Western Dairy Herd Mgmt. Conf., Reno, NV. Agricultural Experiment Station and Cooperative Extension Service, Kansas State University, Manhattan.

Shearer, J. K., and S. R. van Amstel. 2010. Pathophysiology and differentiation of toe lesions in dairy cattle. Pages 253-255 in Forum Proc. Am. Coll. Vet. Intern. Med., Anaheim, CA. American College of Veterinary Internal Medicine, Lakewood, CO.

Shearer, J. K., S. R. van Amstel, M. Benzaquen, and L. C. Shearer. 2006. Effect of season on claw disorders (including thin soles) in a large dairy in the southeastern region of the United States. Pages 110-111 in Proc. 14th Symp. Lameness Ruminants, Colonia del Sacramento, Uruguay. Uruguayan Society of Veterinary Medicine, Buiatrics Branch, Montevideo, Uruguay.

Somers, J. G. C. J., K. Frankena, E. N. Noordhuizen-Stassen, and J. H. M. Metz. 2005. Risk factors for interdigital dermatitis and heel erosion in dairy cows kept in cubicle houses in the Netherlands. Prev. Vet. Med. 71:23-34.

Toussaint-Raven, E., R. T. Halstra, and D. J. Peterse. 1985. Cattle Foot Care and Claw Trimming. Farming Press, Ipswich, UK.

Warnick, L. D., D. Janssen, C. L. Guard, and Y. T. Grohn. 2001. The effect of lameness on milk production in dairy cows. J. Dairy Sci 84:1988-1997.

Whay, H. R., A. E. Waterman, A. J. F. Webster, and J. K. O'Brien. 1998. The influence of lesion type on the duration of hyperalgesia associated with hindlimb lameness in dairy cattle. Vet. J. 156:23-29. 